\title{
Medicina geral e familiar - especialidade ou apenas especial?
}

JAIME CORREIA DE SOUSA*

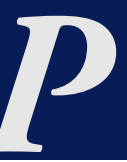
ara muitos médicos de família portugueses é um dado adquirido que a medicina geral e familiar (MGF) é uma especialidade médica de pleno direito: existem diplomas legais que a reconhecem como tal; para aceder à carreira é necessário frequentar um internato de especialidade; e, desde 1984, existe um Colégio de Especialidade da Ordem dos Médicos para a MGF. Os nossos colegas das outras especialidades, através da organização profissional dos médicos Portugueses, reconheceram a existência da especialidade e o Estado Português obrigou-se a regulamentar uma formação específica que se acompanha de um rigoroso processo de avaliação para os médicos de família a exercer em Portugal. Daí que pareça inadequado escrever um editorial sobre $o$ assunto.

Talvez não seja. Se não, vejamos. Foi recentemente colocado em discussão pública um documento que veio avivar velhas feridas. Trata-se de um Projecto de Decreto-Lei que visa a transposição para a legislação Portuguesa da Directiva . $^{\circ}$ 2005/36/CE, do Parlamento e do Conselho Europeus, relativa ao reconhecimento das qualificações profissionais, e da Directiva n. ${ }^{\circ}$ 2006/100/CE, do Conselho, que adapta determinadas directivas no domínio da livre circulação de pessoas, em virtude da adesão da Bulgária e da Roménia. ${ }^{1}$

O objectivo desse projecto é adaptar determinadas directivas no domínio da livre circulação de pessoas, estabelecendo o regime aplicável, no território nacional, ao reconhecimento das qualificações profissionais adquiridas noutro Estado membro da União Europeia por nacional de Estado membro que pretenda exercer, como trabalhador independente ou como trabalhador subordinado, uma profissão regulamentada. Abrange igualmente o reconhecimento das qualificações obtidas fora da União Europeia por nacional de Estado membro, devendo o reconhecimento inicial relativo às profissões a que se refere respeitar as condições mínimas de formação aí previstas. O reconhecimento das qualificações profissionais permite ao titular exercer no território nacional a profissão para a qual está qualificado no Estado membro de origem, nas mesmas condições que os profissionais que adquiriram as qualificações naquele território.

No Artigo $17^{\circ}$ é enunciado o Princípio do reconhecimento automático, segundo o qual as autoridades competentes reconhecem os títulos de formação de médico com formação de base e de médico especialista, constantes dos números 1.1 e 1.3 do anexo II desde que os títulos de formação a reconhecer tenham sido emitidos pelos organismos nacionais competentes. Estas disposições não prejudicam os direitos adquiridos previstos. A autoridade competente reconhece, para o exercício da actividade de médico generalista, no âmbito do Serviço Nacional de Saúde, os títulos de formação referidos no n. ${ }^{\circ} 1.4$ do anexo II, concedidos por outro Estado membro de acordo com as condições mínimas de formação estabeleci- 
das no artigo $25^{\circ}$, sem prejuízo do disposto no artigo $27^{\circ}$. O diploma separa assim o reconhecimento do título de especialista do título de generalista.

No diploma são definidos os tempos mínimos de formação para as diferentes especialidades que são diferentes dos tempos obrigatórios regulamentados em Portugal. É curioso que o diploma prevê como tempo mínimo de formação de algumas especialidade médicas, como por exemplo a Anestesiologia, a Oftalmologia, a Otorrinolaringologia ou a Endocrinologia de apenas três anos, quando estas têm mais tempo em Portugal. Cai assim por terra um dos argumentos oficiosos que tem sido avançado para negar à MGF a pretensão de passar a ter quatro ou mais anos de formação, o facto de, a nível da União Europeia, apenas serem necessários três. Existem outras especialidades com esse tempo mínimo e que, no nosso País, têm exigências de tempo de formação superiores.

Para os colegas mais habituados às andanças das organizações internacionais, e particularmente os que, através da Ordem dos Médicos, têm representado a MGF Portuguesa na UEMO (União Europeia dos Médicos de Clínica Geral/Medicina Familiar) ou no CPME (Comité Permanente dos Médicos Europeus), esta questão não surge como uma surpresa. A discussão da necessidade do reconhecimento oficial, a nivel Europeu, da Especialidade de MGF vem já de longa data. Têm sido tentadas várias formas de resolver o problema, até agora sem êxito.

As sucessivas recomendações da Comissão Europeia (CE) sobre a formação médica mínima e direitos adquiridos persistem em manter a MGF numa alínea separada das outras especialidades médicas. E por quê? Vários países da União Europeia como a Suécia, Finlândia, Dinamarca, Alemanha, Irlanda, Espanha e Portugal, para citar apenas alguns dos mais antigos membros, reco- nhecem a Especialidade de MGF há já muitos anos. O reconhecimento tem encontrado mais obstáculos em países como a Itália ou a França (que a reconheceu recentemente) e, pasme-se, o Reino Unido, onde apesar de uma formação específica em clínica geral de elevada qualidade, tem persistido a definição clássica de "general practitionen" como generalista vs. "consultant" ou especialista hospitalar. Só este ano a BMA (British Medical Association) e o RCGP (Royal College of General Practitioners) voltaram a abrir o debate para o reconhecimento formal, na lei, de algo que, na prática, já vem a acontecer há muito tempo.

São várias as causas desta atitude especial da CE para com o reconhecimento do título de especialista em medicina geral e familiar. Desde o início da formação da Comunidade Económica Europeia, mais tarde Comunidade Europeia e hoje União Europeia (UE), que foram detectadas diferenças consideráveis entre países quanto à concepção da necessidade de uma formação para os médicos generalistas e quanto ao conteúdo e duração da mesma; havia demasiados profissionais no terreno que passaram a beneficiar de direitos adquiridos para a prática da medicina geral e que, por isso, resistiram a um processo de formação profissional ou re-qualificação; na maior parte dos países as suas associações profissionais apoiaram essa atitude e os respectivos ministérios de tutela consideraram que o investimento em formação seria demasiado pesado tendo preferido manter o "status quo". Na maioria dos Estados Membros, ao longo de todos estes anos, o reconhecimento do título de generalista dependeu sempre mais das definições de cada organismo nacional competente do que da existência ou não de uma formação específica ou do seu conteúdo. Sendo assim, em alguns Estados Membros a formação mínima estruturada em MGF foi sendo protelada por 
razões mais ou menos discricionárias ou como resultado da falta de financiamento, insuficiência de incentivos ou pela resistência dos profissionais.

Houve países que atrasaram até ao limite o processo de institucionalização da formação dos médicos de família de acordo com as normas e directivas europeias, tal como a França e a Itália. Foram poucos aqueles que, tal como Portugal, decidiram dinamizar uma formação dos profissionais já em exercício, em parte por que, desde o início, a carreira de clínica geral nascera já com essa opção expressa no diploma legal que instituiu as carreiras médicas. ${ }^{2}$

Outro obstáculo tem sido a resistência mais ou menos passiva, por vezes algo activa das estruturas profissionais nacionais ou europeias das outras especialidades que nem sempre vêm com bons olhos esta carta de alforria da MGF. Os juristas, os membros das múltiplas comissões e sub-comissões e os euroburocratas têm sido igualmente preciosos aliados da manutenção do estado de coisas.

Outra causa importante poderá ter sido a relação que existe entre o perfil e tipo de exercício da MGF em cada país com o modelo de organização dos cuidados de saúde primários. Existem muito maiores semelhanças entre serviços hospitalares da mesma especialidade na Europa do que entre a organização e prática da medicina geral entre os mesmos países. Nestas circunstâncias, definir as competências nucleares e o perfil profissional do médico de família europeu não foi tarefa fácil; com a publicação pela WONCA da definição europeia de Medicina Geral e Familiar, ${ }^{3}$ que realça mais os objectivos a atingir e as afinidades da MGF nos diferentes contextos de prática do que as diferenças entre eles, muito dependentes dos condicionalismos nacionais do contexto de organização do exercício, tornou-se ainda mais clara a possibilidade de se conseguir legislar sobre os critérios minimos para uma formação específica em MGF na União Europeia. Os sucessivos alargamentos da Comunidade não facilitaram a tarefa; de cada vez que entram novos países, há que proceder à normalização e reconhecimento mútuo de diplomas e surgem os inevitáveis "direitos adquiridos» que voltam a protelar o reconhecimento da MGF como especialidade.

\section{O que podemos fazer? Como promover o reconhecimento da especialidade de MGF na Europa?}

Portugal já fez grande parte do que tinha a fazer. Desde o primeiro diploma das carreiras médicas, o DL 310/82, que temos uma definição de um perfil profissional, completado mais tarde pelo histórico documento da APMCG de 1990, "Um futuro para a medicina de família em Portugal ${ }^{4}$ e pelo importante documento do Colégio de Especialidade da Ordem dos Médicos de 1995, «Um novo curriculum para uma nova especialidade", ${ }^{5}$ bem assim como pelos numerosos contributos posteriores da APMCG e do Colégio de Especialidade. Construíram-se e reviram-se programas de formação em MGF de elevada qualidade. Existe já o ensino da MGF na totalidade das escolas médicas Portuguesas. Na carreira de MGF só podem, em princípio, ingressar médicos que completaram a formação em MGF ou viram os seus direitos reconhecidos ao abrigo dos diplomas europeus, apesar de, devido à falta de profissionais no terreno, se contratarem frequentemente médicos sem o título de especialidade de MGF para contratos de curta duração, em clara violação das normas em vigor.

\section{O que está a ser feito?}

O reconhecimento da MGF como especialidade a nivel Europeu tem estado na agenda de prioridades da UEMO que lhe dedicou um dos seus Grupos de 
Trabalho. Na última reunião realizada em Toledo em 26 e 27 de Outubro passado, foram dados alguns passos que irão permitir uma acção concertada das organizações representativas da medicina familiar nos diferentes países. A Presidência da UEMO é da responsabilidade Portuguesa desde o início de $2007 .{ }^{\dagger}$ Um dos compromissos da Presidência e uma das prioridades actuais da Organização é exactamente o reconhecimento da Especialidade de MGF. Sendo Portugal um dos países que já a aceitam há mais tempo, os nossos dirigentes actuais e futuros da Ordem dos Médicos têm, por isso, uma obrigação acrescida de apoiaram as diligências junto do Ministério da Saúde para que o Governo solicite junto da UE a inscrição da MGF na lista das Especialidades médicas.

\section{O que falta então fazer?}

Para o reconhecimento de uma especialidade a nivel da UE é necessário que pelo menos $2 / 5$ dos estados membros (actualmente vinte e sete) o solicitem. Cabe pois ao governo de cada país onde a MGF é uma especialidade reconhecida informar disso a CE e solicitar que sejam iniciados os procedimentos legislativos para a inclusão da especialidade na Directiva.

Para além disso, é necessário que exista acordo quanto ao período minimo de formação necessário. O estabelecimento desse período mínimo de formação é resolvido por um procedimento de comitologia. Os comités de comitologia são formados a nivel da UE por representantes dos Estados Membros; as decisões dos comités são obtidas por maioria qualificada de votos e os países têm pesos diferentes em função da população que representam (por ex. a Ale-

† Composição da Presidência da UEMO:

Presidente: Isabel Caixeiro

Secretário-Geral: Luís Filipe Gomes

Tesoureira: Manuela Santos

Delegação Portuguesa à UEMO: Jaime Correia de

Sousa (Chefe de Delegação) e Luiz Miguel Santiago manha e França têm 29 votos cada e a Grécia e Portugal apenas 12).

Como é óbvio, este assunto não está na agenda dos ministros de nenhum Estado Membro da UE. Ainda por cima o ministério em causa varia de país para país; nuns casos é o ministério da saúde, noutros da educação, noutros ainda da segurança social. Só por solicitação e insistência das organizações profissionais médicas de cada país poderá o respectivo governo tomar essa iniciativa. E nem todas as organizações médicas vêm o problema da mesma forma; é necessário que as associações nacionais e europeias de médicos de família persistam em colocar esta questão na agenda política das organizações médicas até obterem apoio para que estas pressionem os respectivos governos. Não parece tarefa fácil, mas é a única via.

Dois argumentos de peso na discussão com os governos são o direito dos cidadãos a um médico de família com elevados padrões de qualidade de formação, bem assim como o direito dos médicos à livre circulação na UE.

$\mathrm{Na}$ literatura médica existem igualmente vários argumentos sólidos que reconhecem que a capacidade dos sistemas de saúde para prestarem cuidados de alta qualidade e custo-efectivos está ligada à existência de um sector de cuidados de saúde primários florescentes. ${ }^{6}$ Existe também forte evidência de que um médico de família devidamente qualificado é um elemento essencial nos sistemas de cuidados de saúde primários e que os resultados dos sistemas de saúde estão relacionados com a qualidade dos cuidados de saúde primários existentes nesse país. ${ }^{7}$

É óbvio que os argumentos que salientam as vantagens para o sistema de saúde da existência de médicos de família com boa formação profissional esbarram com a inércia, com os interesses instalados e com a agenda politica dos governos. Daí que a nossa pressão 
deva ser constante e determinada.

\section{Que consequências existem} para a formação dos futuros médicos de familia?

Tranquilizem-se os jovens médicos, os internos de MGF ou os estudantes de medicina que vêm na especialidade uma hipótese de realização profissional. Estas hesitações e contradições da burocracia europeia pouco ou nada afectam o futuro da MGF em Portugal, bem assim como a qualidade da formação.

Apesar de, a nivel Europeu, a MGF não ser ainda considerada uma especialidade, os tempos minimos de formação de três anos e algumas regras quanto aos locais e serviços onde a formação pode ser obtida estão regulamentados no diploma em questão (Directiva n. ${ }^{\circ}$ 2005/36/CE).

Não sendo oficialmente designada como especialidade, na prática começa-se a desenhar um cenário europeu em que a formação nuclear em MGF tende a harmonizar-se em torno das recomendações da WONCA. Em Portugal os passos já dados para a promoção da qualidade da formação e a reforma em curso que permitirá uma prática clínica de maior qualidade, são os garantes da força e solidez da profissão.

Para os médicos de família Portugueses o problema do reconhecimento da especialidade de MGF a nivel europeu coloca-se sobretudo numa perspectiva de defesa da qualidade e da dignidade da especialidade e pela exigência de solidariedade para com os colegas de outros países.

Todos sabemos que a MGF é uma área de actividade muito especial; gostaríamos que, de pleno direito, passasse também a ser uma especialidade.

\section{REFERÊNCIAS BIBLIOGRÁFICAS}

1. Ministério do Trabalho e da Solidariedade Social. Projecto de Decreto-Lei de transposição para a ordem jurídica interna da Directiva n. ${ }^{\circ}$ 2005/36/CE, do Parlamento Europeu e do Conselho, de 7 de Setembro, relativa ao reconhecimento das qualificações profissionais, e da Directiva n. ${ }^{\circ}$ 2006/100/CE, do Conselho, de 20 de Novembro, que adapta determinadas directivas no domínio da livre circulação de pessoas, em virtude da adesão da Bulgária e da Roménia. Separata BTE, n. ${ }^{\circ} 6$, 3/10/2007.

2. Ministério das Finanças e do Plano, dos Assuntos Sociais e da Reforma Administrativa. Decreto-Lei no 310 / 82 de 3 de Agosto. Diário da República, 1982; I Série, no 177 : 2283$-98$.

3. World Organization of Family Doctors (WONCA). A Definição Europeia de Medicina Geral e Familiar (Clínica Geral/ Medicina Familiar). WONCA EUROPA 2002. Disponivel em: URL: http://www.apmcg.pt/document/714 79/457322.pdf [acedido em 4/11/2007].

4. Associação Portuguesa dos Médicos de Clínica Geral, Direcção Nacional. Um futuro para a medicina de família em Portugal. Lisboa: APMCG; 1991. Disponível em: URL: http:// www.apmcg.pt/document/71479/448829. doc [acedido em 4/11/2007].

5. Ordem dos Médicos. Colégio de Clínica Geral. Um novo curriculum para uma nova especialidade. Lisboa: Ordem dos Médicos; 1995.

6. Boerma WG, Fleming, DM. The role of general practice in primary health care. London: The Stationery Office; 1998.

7. Macinko J, Starfield B, Shi L. The contribution of primary care systems to health outcomes within Organization for Economic Cooperation and Development (OECD) countries, 1970-1998. Health Ser Res 2003 Jun; 38 (3): 831-65. 